\title{
Soil erosion affects variations of soil organic carbon and soil respiration along a slope in Northeast China
}

\author{
Tong Li ${ }^{1}$, Haicheng Zhang ${ }^{2}$, Xiaoyuan Wang ${ }^{1}$, Shulan Cheng ${ }^{3}$, Huajun Fang ${ }^{4}$, Gang Liu ${ }^{1}$ and Wenping Yuan ${ }^{5,6^{*}}$
}

\begin{abstract}
Background: Although soil erosion plays a key role in the carbon cycle, a holistic and mechanistic understanding of the soil erosion process within the cycle is still lacking. The aim of this study was therefore to improve our mechanistic understanding of soil organic carbon (SOC) and soil respiration dynamics through an experiment conducted in an eroding black soil farmland landscape in Northeast China.

Results: The depositional profiles store 5.9 times more SOC than the eroding profiles and 3.3 times more SOC than the non-eroding profiles. A linear correlation between the SOC and ${ }^{137} \mathrm{Cs}$ (Caesium-137) was observed in our study, suggesting that the SOC decreased with increased soil erosion. Furthermore, the fractions of intermediate $\mathrm{C}$ and the microaggregate $\mathrm{C}$ were lowest at the eroding position and highest at the depositional position. In the depositional topsoil, the input of labile materials plays a promotional role in soil respiration. Conversely, in the subsoil (i.e., below $10 \mathrm{~cm}$ ), the potential mineralization rates were lowest at the depositional position-due to effective stabilization by physical protection within soil microaggregates. The field results of soil surface respiration also suggest that the depositional topsoil SOC is prone to be mineralized and that SOC at this depositional context is stabilized at subsoil depth. In addition, the high water contents at the depositional position can limit the decomposition rates and stabilize the $\mathrm{SOC}$ at the same time.

Conclusions: The findings from this study support that a majority of the $\mathrm{SOC}$ at footslope is stored within most of the soil profile (i.e., below $10 \mathrm{~cm}$ ) and submitted to long-term stabilization, and meanwhile support that the depositional profile emits more $\mathrm{CO}_{2}$ than the summit due to its high amount and quality of $\mathrm{SOC}$.
\end{abstract}

Keywords: Soil erosion, Soil organic carbon, Soil respiration, Sloping farmland

\section{Introduction}

As the largest terrestrial carbon pool, the soil carbon pool is approximately 3.3 times the size of the atmospheric pool and 4.5 times the size of the biotic pool (Lal 2004a). Soil erosion and the subsequent transport of sediments by rivers represent a key pathway for soil carbon lateral transfer at the land surface, which has a profound effect on the carbon budget of terrestrial ecosystems (Ludwig et al. 1996; Li et al. 2018; Wang et al. 2019). However,

\footnotetext{
* Correspondence: yuanwpcn@126.com

${ }^{5}$ Guangdong Province Key Laboratory for Climate Change and Natural disaster Studies, School of Atmospheric Sciences, Sun Yat-sen University, Zhuhai 519082, China

${ }^{6}$ Southern Marine Science and Engineering Guangdong Laboratory, Zhuhai

519082, China

Full list of author information is available at the end of the article
}

propositions that soil erosion induces a carbon source or sink have been highly debated (Lal and Pimentel 2008). Previous studies have generally concluded that soil erosion leads to a terrestrial carbon loss due to the breakdown of structural aggregates and lower productivity in the eroding areas resulting from decreased soil nutrient (Jacinthe et al. 2002; Lal 2004b). In contrast, other studies from the last two decades have shown that soil erosion can induce a terrestrial carbon sink, due to the transfer and burial of high soil organic carbon (SOC) from eroded soil surface areas to depositional landform positions (Stallard 1998; Van Oost et al. 2007). The differences in understanding of the role of soil erosion in the carbon cycle reflect the uncertainties in quantifying a vertical flux controlled by interacting processes at large spatial and temporal scales. To better assess the erosion-induced terrestrial carbon 
sink or source at large scales, mechanisms involved in impacting carbon storage and flux need to be explored in detail at the landscape scale.

Within the landscape scale, soil lateral redistribution processes induced by water and tillage erosion can often affect carbon cycle dynamics. Initially, soil erosion may reduce plant production as a result of soil degradation and may decrease soil nutrient levels due to decomposition at eroding sites (Stallard 1998; Harden et al. 1999). Furthermore, initial deep burials of SOC can inhibit decomposition at deposition sites (Smith and Buddemeier 2005; Yoo et al. 2005). Moreover, the chemical or physical breakdown of soil can increase the decomposition of SOC during the detachment and transport processes (Lal 2003). In recent years, some models combining geomorphic factors with carbon dynamics have provided strong support for the assertion that lateral fluxes exert an important control on carbon vertical exchange at the landscape scale (Liu et al. 2003; Van Oost et al. 2005; Rosenbloom et al. 2006). Previous experimental studies have been conducted to investigate the observational mechanisms in eroding agricultural landscapes (Doetterl et al. 2012; Wiaux et al. 2014a; Wiaux et al. 2014b) or under natural vegetation conditions (Berhe et al. 2008; Berhe et al. 2012; Nadeu et al. 2012). However, a full mechanistic understanding of the effect of soil erosion and burial processes on vertical carbon dynamics (such as soil respiration, aboveground respiration, plant production, etc.) is still lacking (Kuhn et al. 2012). Specifically, the impacts of soil erosion on soil respiration (Rs), which is one of the most important ecological processes within our ecosystem, is still unclear.

Soil respiration is the largest vertical carbon efflux from soil to atmosphere and has the considerable potential to induce atmospheric carbon dioxide concentration variation-an increasingly alarming issue in context of global climate change (Yu et al. 2017). Soil respiration can indicate soil mineralization through SOC decomposition via microbes and can be affected by numerous factors including, but not excluding, soil temperature, soil moisture, and physical protection within soil aggregates (Doetterl et al. 2016). Thus, understanding mechanisms involved in soil respiration efflux is essential and has great research value for quantifying an erosion-induced vertical carbon flux.

Northeast China is a primary and important food production area in China, owing to its fertile soil which has a high organic matter content. However, after approximately 100 years of intense cultivation, the soil has been severely damaged by soil erosion (Zhang et al. 2007). Severe soil erosion has occurred since large-scale land reclamation began in the 1950s, and the thickness of black soils has decreased from 60 to $70 \mathrm{~cm}$ in the 1950 s to $20-30 \mathrm{~cm}$ at present (Fang et al. 2012), exposing the loess parent material in some areas. Overall, approximately $4470 \mathrm{~km}^{2}$ of land in Northeast China has been subject to moderate to severe soil erosion, accounting for $38 \%$ of the total black soil acreage (Fang et al. 2006). Presently, there are few observational studies in Northeast China that explore the effects of soil erosion on SOC distribution and soil surface respiration fluxes at the landscape scale. However, the severe soil erosion in Northeast China highlights an urgent need to investigate the impacts of soil erosion processes on the carbon cycle.

The goal of this study was to conduct an experiment to improve our mechanistic understanding of SOC redistribution dynamics in an eroding black soil farmland landscape. We mainly focus on the SOC stocks and soil respiration dynamics in this study. Thus, our study was conducted as follows: First, we measured soil surface respiration fluxes along the cultivated slope, calculated the horizontal and vertical distribution of the SOC stocks, and quantitatively estimated the soil redistribution rate using ${ }^{137} \mathrm{Cs}$ measurements. Second, we assessed the differences in the SOC pool composition and potential soil respiration along a geomorphic gradient through soil organic matter fractionation and incubation experiments. Third, we analyzed all results and assessed connections among them. In this paper, potential soil respiration represents soil respiration in optimal conditions for microbial activity and SOC decomposition-without the impacts of the varied soil water and temperature conditions.

\section{Materials and methods \\ Study site}

The study site is located at the Heshan Farm $\left(125^{\circ} 20^{\prime}\right.$ $10.5^{\prime \prime}$ E, 49 $\left.9^{\circ} 00^{\prime} 23.1^{\prime \prime} \mathrm{N}\right)$ in Nenjiang County, Heilongjiang Province, Northeast China. The elevation of the area is 320 to $370 \mathrm{~m}$ above sea level. The slopes of cultivated land in this region range from 0.4 to $8.4 \%$-with an average value of $4.2 \%$. The climate is a semi-humid continental climate with a long cold winter, where the lowest and highest temperatures are $-20{ }^{\circ} \mathrm{C}$ in January and $21{ }^{\circ} \mathrm{C}$ in July, respectively (Zhang et al. 2007). The annual precipitation ranges from 300 to $750 \mathrm{~mm}$, with an average of $534 \mathrm{~mm}$ and more than $90 \%$ of the precipitation falls between May and September (Liu et al. 2013). The primary soil type in this area is black soil, according to the Chinese genetic classification. The main textural classes of the topsoil are silt clay loam to clay loam, according to the USDA classification, with a sand content of $8-27 \%$, a silt content of $29-66 \%$, and a clay content of $26-40 \%$ (Wu et al. 2008). The study site was originally covered by natural forests and pastures and began to be converted into cultivated lands, particularly on the gentlest slopes, due to the needs of a dramatically increasing population and expropriation by ranches in 
the 1950s (Liu et al. 2015). In specific regard to the study site, soybean is the major crop, in rotation with wheat and corn.

\section{Field experiment}

We collected soil cores at four topographic positions (summit A1, convex shoulder A2, backslope A3 and footslope A4) along a hillslope (Fig. 1) at the study site before sowing in May 2015, and sampling was repeated three times at each location. Soil profiles were excavated down to the parent materials at each position. Soil samples were collected at $10-\mathrm{cm}$ intervals for the top $30 \mathrm{~cm}$ soil depth and at 20-cm intervals for soils below $30 \mathrm{~cm}$ deep. In this study, the depth of fertile black soil at convex A2 and backslope A3 is approximately $30 \mathrm{~cm}$ due to serious soil erosion. In addition, our sampling was only one transect along the hillslope, leading to the lack of replicates at slope level. That is due to the limited width of the hillslope and other inoperable factors such as ground holes, etc.

Soil bulk density, carbon content, and ${ }^{137} \mathrm{Cs}$ concentration were measured for each soil layer. The soil bulk density was measured using the oven-dried weight (drying at $105{ }^{\circ} \mathrm{C}$ for $24 \mathrm{~h}$ ). SOC contents were measured using an elemental analyzer (vario EL III, Elementar, Hanau, Germany) as the black soils $(\mathrm{pH}<7)$ were carbonate free, whereas ${ }^{137} \mathrm{Cs}$ was measured using HPGe co-axial detectors coupled to a multi-channel analyzer. To minimize the uncertainties associated with the precision of the ${ }^{137} \mathrm{Cs}$ measurements, ${ }^{137} \mathrm{Cs}$ was detected at $662 \mathrm{keV}$ using counting times at approximately 30,000 s. This method provides results with a counting error of less than $10 \%$ at the $95 \%$ confidence level. Concentrations were then converted into inventories per unit area using the soil depth and bulk density values. Estimates of soil loss and gain rates $\left(\mathrm{t} \mathrm{ha}^{-1} \mathrm{year}^{-1}\right)$ can be derived from the ${ }^{137} \mathrm{Cs}$ measurements by comparing the inventories

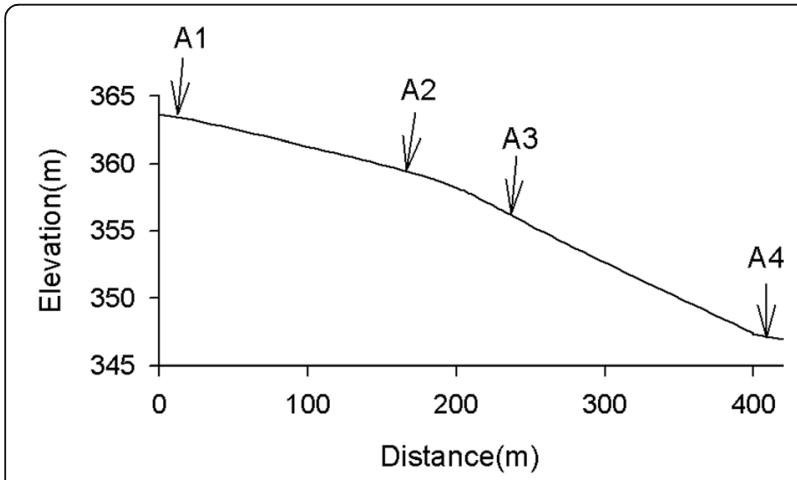

Fig. 1 Topographical transects and sampling point locations for the study site. A1: non-eroding profile, A2 and A3: eroding profiles, A4: depositional profile measured at a specific point with the reference inventory. The reference ${ }^{137} \mathrm{Cs}$ inventory of $2506 \mathrm{~Bq} \mathrm{~m}^{-2}$ is regarded as reliable in the study region (Fang et al. 2012). For an eroding site where the total ${ }^{137} \mathrm{Cs}$ inventory is less than the reference inventory, soil erosion rates can be estimated using the simplified mass balance model proposed by Zhang et al. (1990). For the depositional position, the deposition rates were estimated using the proportional model proposed by Lowrance et al. (1988). The soil redistribution rates include the soil erosion rates at the eroding positions and the soil deposition rates at the depositional positions.

Soil temperature, soil moisture, and soil respiration measurements were conducted once a month during the growing season (May, June, July, and September) in 2015. We conducted field measurements at four topographic positions (Fig. 1) along the slope at the same time of each sample collection day. Soil temperature was measured with a portable digital thermometer. The volumetric moisture was measured using time-domain reflectometry (TDR300, Spectrum Technologies, USA). To better assess the soil respiration process and the SOC dynamics, samples (L1: 0-10, L2: 10-20, L3: 20-30, L4: 30-50, L5: 50-70, and L6: 70-90 cm) from these four slope positions (Fig. 1) were employed for the incubation experimentssoil respiration was measured using a Li-6400XT-09 Soil $\mathrm{CO}_{2}$ Flux Chamber (LI-COR, USA). The respiration of 50 -g soil was monitored during a period of 182 days while keeping moisture (at $55 \%$ of the soil water-holding capacity) and temperature $\left(20^{\circ} \mathrm{C}\right)$ constant in an Erlenmeyer flask. The headspace air was sampled eight times during the incubation period using a gas-tight syringe. Before gas sampling, the headspace air in the flasks was thoroughly flushed with ambient air for $15 \mathrm{~min}$. The flask was then capped immediately by sealing it with a rubber stopper for $3 \mathrm{~h}$. The flasks were flushed with ambient air again after sampling and maintained with sealing membrane and the $\mathrm{CO}_{2}$ emission was detected by a gas chromatograph (Agilent 7890A, USA). In our analysis, we only considered the average respiration rates when heterotrophic soil respiration had stabilized.

We also conducted SOC fractionation experiments for the soil layers (L1: 0-10, L3: 20-30, and L5: 50-70, and for the depositional position, L6: 70-90 cm was added) at these four topographic positions (Fig. 1) to isolate the functional SOC fractions. We used the modified scheme described by Doetterl et al. (2012), which was based on the method proposed by Six et al. (1998), as a means of collecting and analyzing data. Through a series of physical and chemical fractionation techniques, we identified different particle sizes of SOC, i.e., water-stable macroaggregate $\mathrm{C}(>250 \mu \mathrm{m})$, microaggregate $\mathrm{C}(250-53 \mu \mathrm{m})$, silt $\mathrm{C}$ $(53-2 \mu \mathrm{m})$, and clay $\mathrm{C}(<2 \mu \mathrm{m})$. Furthermore, three functional SOC pools (fast, intermediate, and passive), 
that differentiate in terms of stabilization mechanisms, were quantitatively estimated according to the method described by Doetterl et al. (2012).

\section{Analyses}

Statistical tests for differences between the means of the geomorphic classes have been performed for the whole dataset, with tests for top and subsoil samples conducted separately using Bonferroni corrections and Tamhane's T2 with SAS Enterprise 4.2 (SAS Institute Inc., Cary, NC, USA). Data for all four locations where aggregated together and linear regressions where performed to link SOC quality and respiration data to soil depth and quantitative estimates of soil redistribution rates.

\section{Results}

Spatial patterns of soil moisture, temperature, and bulk density

During the growing season, the average soil moisture content varied at different slope positions. Along the topographical gradient, the soil moisture content generally declined with increasing altitude, except in the backslope A3 position. The lowest moisture was observed at backslope A3 and the highest moisture at footslope A4 (not shown). We found no evidence for systematic spatial differences in the temperature and the bulk density along the hillslope (not shown).

\section{Soil erosion and soil organic content patterns}

Based on the ${ }^{137} \mathrm{Cs}$ measurements, we quantitatively estimated that the soil erosion rates for A1, A2, and A3 were - $3.5 \mathrm{t} \mathrm{ha}^{-1}$ year $^{-1},-47.2 \mathrm{t} \mathrm{ha} \mathrm{year}^{-1}$, and $56.1 \mathrm{t} \mathrm{ha}^{-1}$ year $^{-1}$, respectively, and the soil deposition rate for A4 was approximately $56.9 \mathrm{t} \mathrm{ha}^{-1}$ year $^{-1}$. Thus, we grouped the soil profiles taken along the geomorphic gradient into three classes according to their geomorphic settings: (i) the non- (or slowly) eroding profile at summit position A1, (ii) the eroding profiles on convex shoulder A2 and backslope A3, and (iii) the depositional profile at the footslope position A4. The vertical distribution of the SOC concentrations and inventories at various landscape positions are shown in Fig. 2. The topsoil SOC contents ranged from 8.1 to $24.4 \mathrm{~g} / \mathrm{kg}$ at the four positions. At the eroding positions and the non-eroding position, the SOC concentrations varied by locations and decreased with increasing soil depth. The SOC concentrations were higher for the depositional and the non-eroding profiles than for the eroding profiles. The soils of the depositional profiles were enriched in SOC at subsoil depth and the SOC contents at the footslope position first increased and then decreased with the soil depth (Fig. 2a). The depositional profiles store 5.9 times more SOC than the eroding profiles and 3.3 times more SOC than the non-eroding
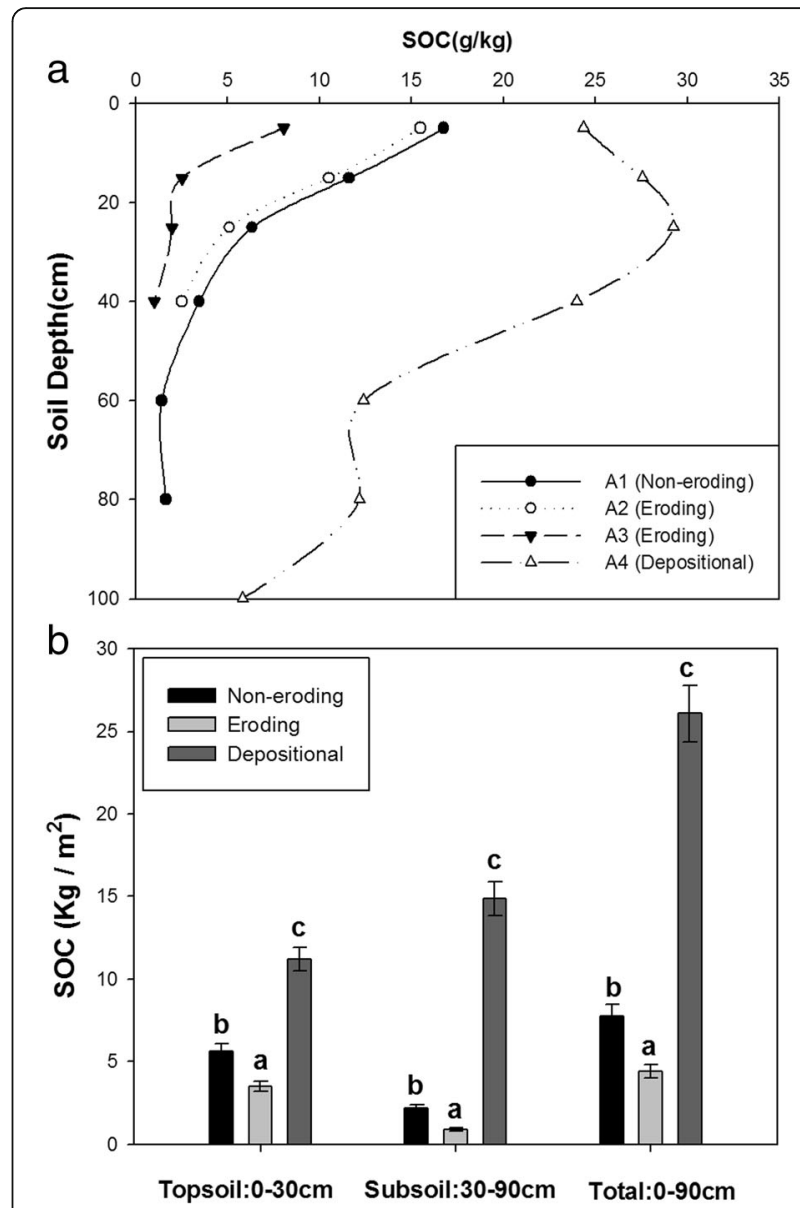

Fig. 2 SOC depth distribution (a) and stocks (b) as a function of the geomorphic position. Statistical tests for differences between the means of the geomorphic classes have been performed for the entire dataset and for top and subsoil samples separately. The same letter indicates no significant difference between the geomorphic positions $(p<0.1)$

profiles (Fig. 2b). The SOC and the ${ }^{137} \mathrm{Cs}$ were positively correlated in our study area, as were the SOC and the soil redistribution rates (Table 1 ).

\section{Spatial distribution of soil respiration}

We found consistent patterns of soil surface respiration fluxes in May, June, July, and September 2015 (Fig. 3a). The respiration rates were highest at the depositional position and lowest at the eroding position. This pattern coincided with the variations in the SOC stocks along the hillslope. When averaged over the period of observation, the ratios of soil respiration $\left(\mu \mathrm{mol} \mathrm{m} \mathrm{m}^{-2} \mathrm{~s}^{-1}\right)$ to the SOC inventory $\left(\mathrm{kg} \mathrm{m}^{-2}\right)$ were compared along the slope. The eroding profiles had a slightly higher Rs/SOC ( $\mu \mathrm{mol} \mathrm{kg} \mathrm{kg}^{-1} \mathrm{~s}^{-1}$ ) than the non-eroding profiles. The Rs/ SOC was lowest at the depositional position for both the 0-30 $\mathrm{cm}$ and the 0-90 cm layers (Fig. 3b). 
Table 1 Significant correlations. Pearson correlation coefficients of linear regressions ( $r$ ) between the soil depth, soil redistribution rate, and SOC parameters. Single and double asterisks indicate the significance levels at $p<0.05$ and $p<0.01$, respectively

\begin{tabular}{|c|c|c|c|}
\hline & Variable 1 & Variable 2 & $r$ \\
\hline \multirow[t]{8}{*}{ Field measurement } & SOC concentration & ${ }^{137} \mathrm{Cs}$ activity $\mathrm{Bq} \mathrm{kg}{ }^{-1}$ & $0.67^{* *}$ \\
\hline & SOC concentration & Soil redistribution rate & $0.85^{* *}$ \\
\hline & SOC stock $\mathrm{kg} \mathrm{m}^{-2}$ & ${ }^{137} \mathrm{Cs}$ inventory $\mathrm{Bq} \mathrm{m}^{-2}$ & $0.96^{*}$ \\
\hline & sOC stock $\mathrm{kg} \mathrm{m}^{-2}$ & Soil redistribution rate & $0.94^{*}$ \\
\hline & Fast Pool C (\% of total SOC) & Soil depth & $-0.56^{*}$ \\
\hline & Passive pool C (\% of total SOC) & Soil depth & $0.56^{*}$ \\
\hline & Intermediate pool C (\% of total SOC) & Soil redistribution rate & $0.74^{*}$ \\
\hline & Microaggregate C (\% of total SOC) & Soil redistribution rate & $0.67^{*}$ \\
\hline \multirow[t]{5}{*}{ Incubation study } & Respiration $\mu \mathrm{g} \mathrm{Ch}^{-1} \mathrm{~g} \mathrm{Soil}^{-1}$ & SOC concentration & $0.88^{* *}$ \\
\hline & Respiration $\mu \mathrm{g} \mathrm{Ch}^{-1} \mathrm{~g} \mathrm{Soil}^{-1}$ & Soil depth & $-0.63^{* *}$ \\
\hline & Respiration $\mu \mathrm{g} \mathrm{Ch}^{-1} \mathrm{~g} \mathrm{SOC}^{-1}$ & Soil depth & $-0.58^{* *}$ \\
\hline & Subsoil respiration per SOC & Intermediate Pool C (\% of total SOC) & $-0.65^{*}$ \\
\hline & Subsoil respiration per SOC & Microaggregate $\mathrm{C}$ (\% of total SOC) & $-0.63^{*}$ \\
\hline
\end{tabular}

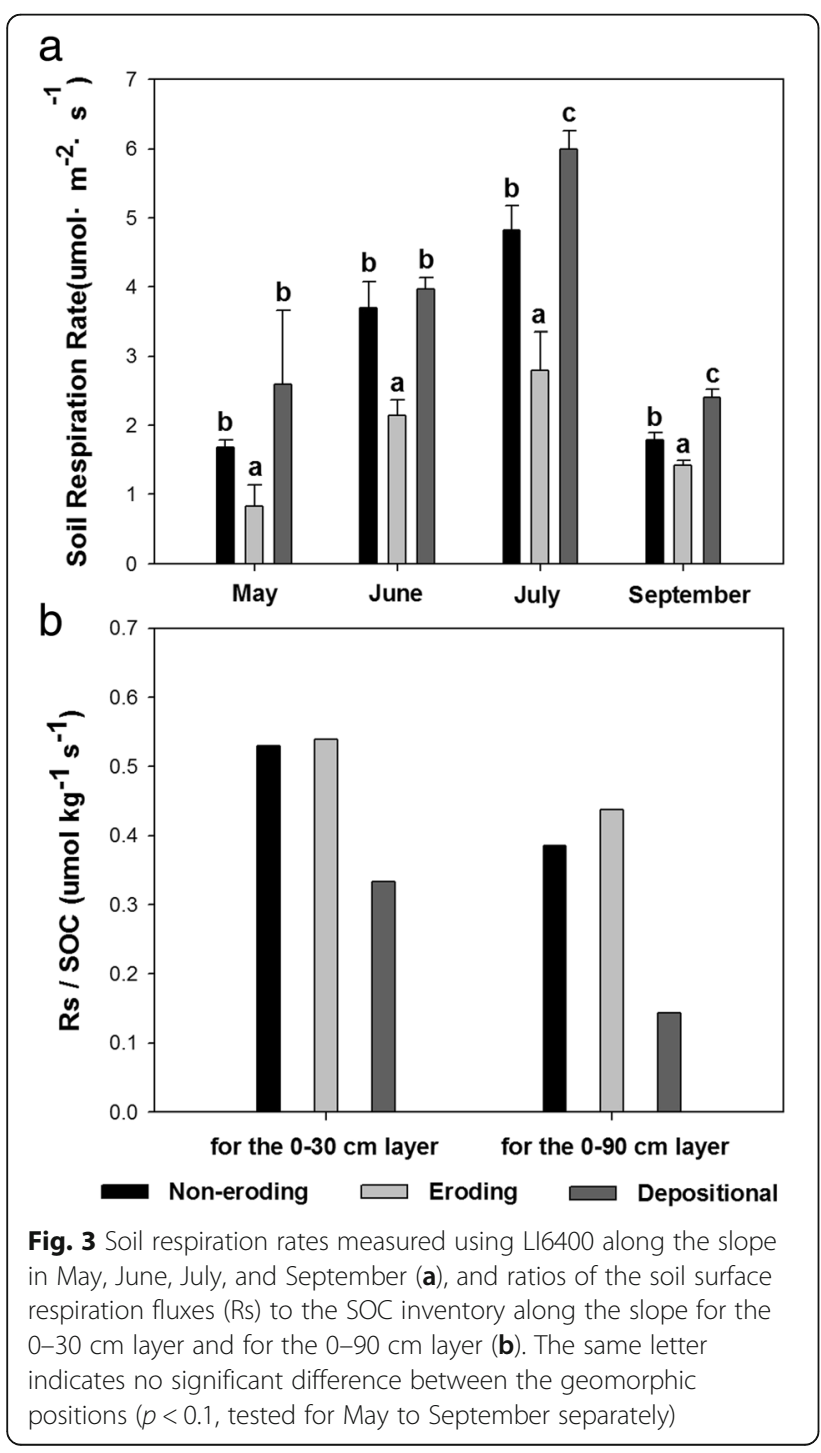

In the incubation experiments, the respiration rates of the topsoil samples $(0-10 \mathrm{~cm})$ were higher than those of the subsurface soils $(10-90 \mathrm{~cm})$ (Fig. 4). The measured respiration rate was negatively correlated with depth, whereas positive correlations with the SOC concentration can be identified (Table 1). The soil respiration per unit soil (g) for the topsoil samples was the lowest at the eroding profiles, while the depositional profiles respired at significantly higher rates (Fig. 4a). For subsurface soils, the highest respiration rates were found for the depositional profiles, and this respiration was significantly higher than the respiration of the non-eroding and eroding profiles $(p<0.1)$ (Fig. 4a).

The topsoil samples also respired at a higher rate than the subsoils per unit SOC (g). For the $0-10 \mathrm{~cm}$ layer, the potential respiration rates were higher at the depositional position than at the non-eroding position (Fig. 4b) . For the subsoil $(10-90 \mathrm{~cm})$, the lowest respiration rates were measured in the depositional profiles and were significantly lower than the respiration rates of the noneroding profiles $(p<0.1)$ (Fig. $4 \mathrm{~b})$. Samples from the eroding profiles respired at a higher rate than those from the depositional or non-eroding profiles (Fig. 4b).

\section{Spatial patterns of the SOC fractions and pools}

We observed a significant positive correlation between the soil depth and the proportion of the passive pool C $(p<0.01)$ and a negative correlation between the soil depth and the fast pool (Table 1). The depositional profiles contained a slightly greater proportion of the SOC in the fast pool relative to the non-eroding or eroding profiles (Fig. 5a). More SOC is associated with the intermediate pool in the depositional profiles than in the non-eroding or eroding profiles (Fig. 5a). We found a significant positive correlation $(p<0.05)$ between the soil 

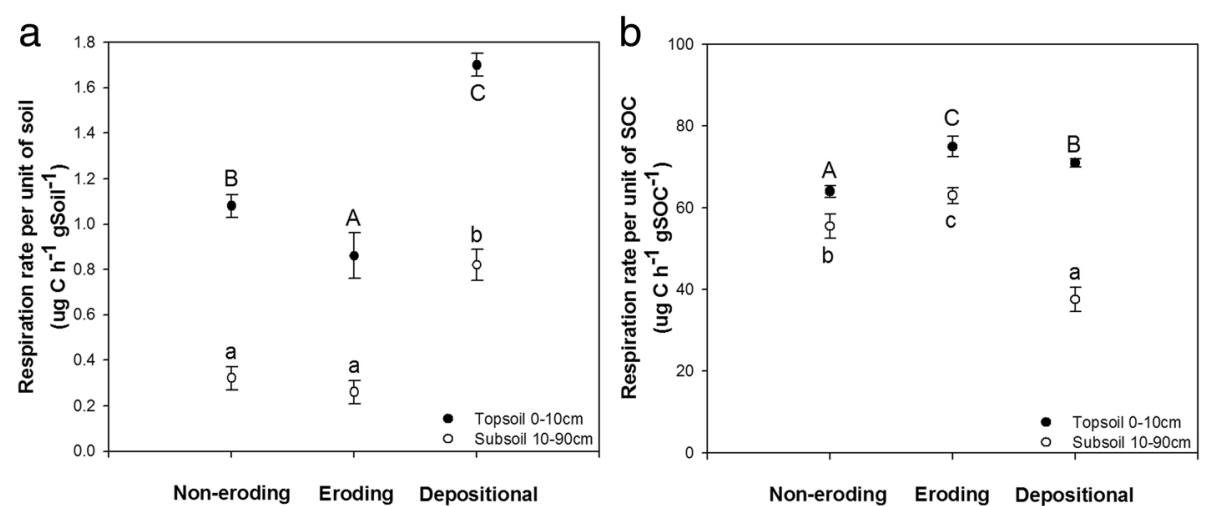

Fig. 4 Observed respiration rates for topsoil and subsoil as a function of the geomorphic position (non-eroding, eroding and depositional). The respiration per unit soil (a) and per unit of SOC (b) is given. The same letter indicates no significant differences between different geomorphic positions for the two depth classes ( $p<0.1$, tested for panel $\mathbf{a}, \mathbf{b}$ separately)
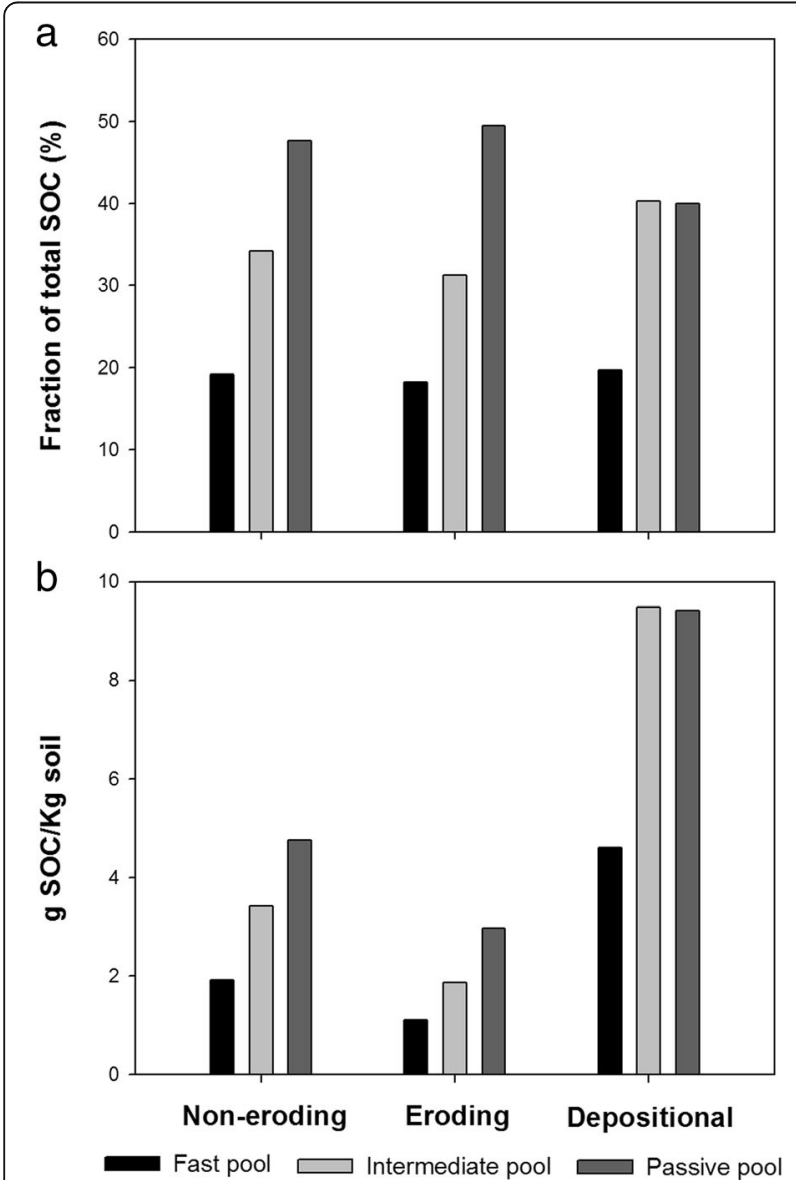

Fig. 5 Distribution of the SOC pools along the geomorphic gradient as a fraction of the total SOC in \% (a) and the absolute amount in $\mathrm{g}$ SOC per kg soil (b) redistribution rates and the fractions of $\mathrm{C}$ in the intermediate pool (Table 1, Fig. 6b) and in microaggregates (Table 1). Proportionally more SOC was stored in the intermediate pool and in the microaggregates at the depositional position. This intermediate pool can mainly reflect the contribution of the microaggregate $\mathrm{C}$ in our study. We also observed a significant negative correlation $(p<0.05)$ between the intermediate pool (or the microaggregate $C$ ) and the subsoil potential respiration per unit SOC (Table 1).

\section{Discussion}

Effects of soil redistribution on the SOC

Our study showed that the depositional profiles were enriched in SOC at subsoil depth and that they stored significantly more SOC than the non-eroding or eroding profiles (Fig. 2), which is consistent with many previous studies (Berhe et al. 2008; Doetterl et al. 2012; Wang et al. 2013; Wiaux et al. 2014a). A previous study showed that SOC depletion took place at eroding sites and SOC accumulation took place at depositional sites (Dlugoß et al. 2012). Being a selective process, soil erosion preferentially transfers fine and light materials, which are typically enriched in SOC relative to the bulk soil (Wairiu and Lal 2003). This process can lead to carbon loss in the eroding profiles and enrichment of the labile $\mathrm{C}$ fraction in the depositional profiles. For example, Wiaux et al. (2014a) observed a spatial differentiation of the labile SOC pool (i.e., the $\mathrm{SOC}$ not resistant to $\mathrm{NaOCl}$ ), with a significant enrichment for the $0-1 \mathrm{~m}$ layer in the depositional profiles along a hillslope in the Belgian agricultural loam belt. In our study, we also observed a greater proportion of SOC in the fast pool at the depositional position (Fig. 5a), which can confirm the processes preliminarily. The SOC concentrations and the fractions of fast $\mathrm{C}$ and intermediate $\mathrm{C}$ were higher at the depositional position; thus, it should be discussed separately on whether the lower respiration 

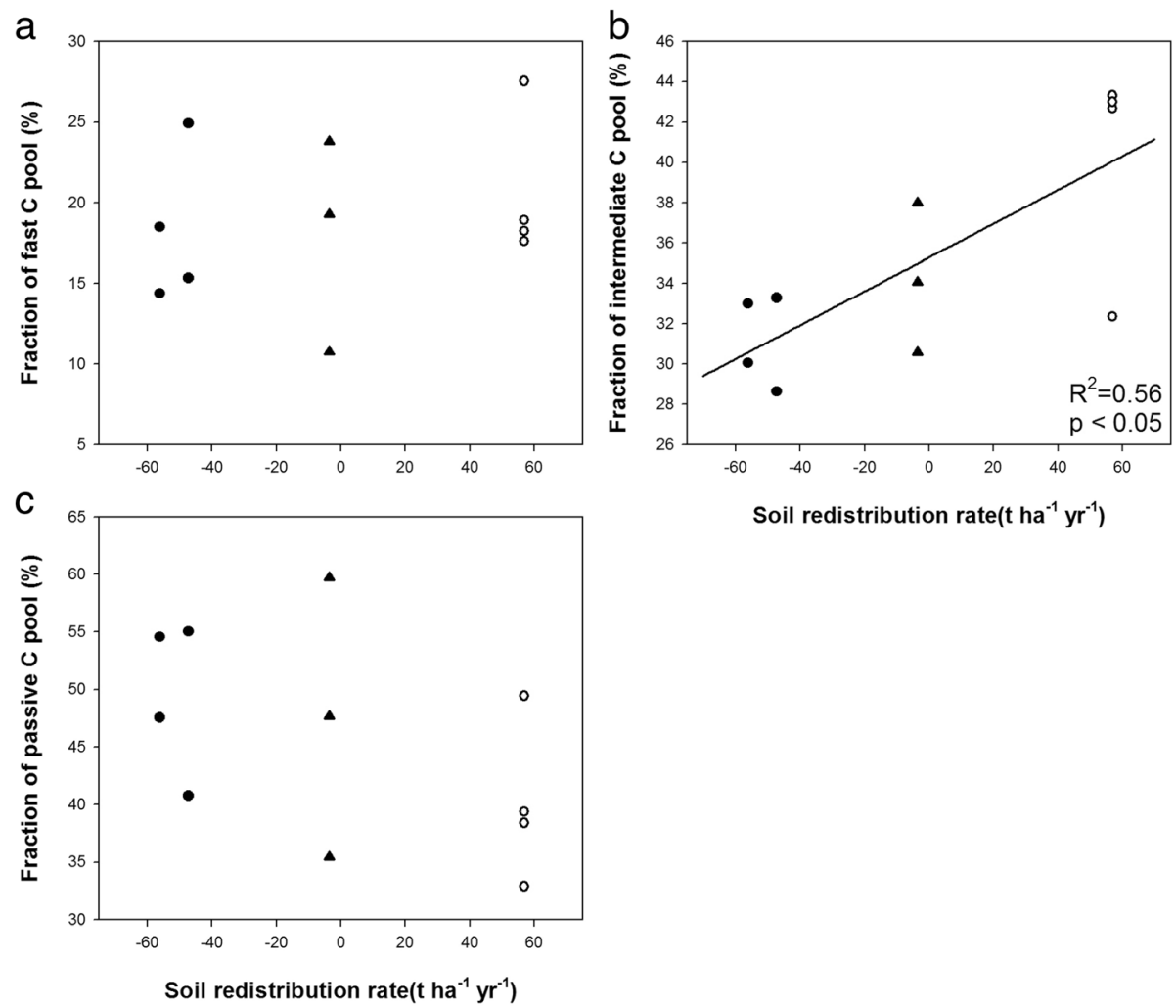

Soil redistribution rate(t $\left.\mathrm{ha}^{-1} \mathrm{yr}^{-1}\right)$

Fig. 6 The changing contribution of the fast C fractions (a), the intermediate C fractions (b) and the passive C fractions (c) along the slope (noneroding position: triangle, eroding position: solid dots, depositional position: hollow circles). The fractions of the intermediate $\mathbf{C}$ (b) are significant and high $(\mathrm{p}<0.05)$ at the depositional position (high soil redistribution rates)

rates per unit SOC benefited from the effective physical protection there.

\section{Controls on potential soil respiration}

We conducted incubation experiments to quantify the potential soil respiration without the impacts of the varied soil water and temperature conditions. Soil incubation studies are advantageous for assessing the SOC decomposition rates of different $\mathrm{C}$ fractions, as there is usually no new input of organic material during the course of an incubation study and the fast $\mathrm{C}$ pool is depleted without being replaced (Schädel et al. 2013). Soil incubation studies lasting longer than 100 days can reduce the dominance of the fast $\mathrm{C}$ pool and will show the contributions of the more recalcitrant pools in context of soil $\mathrm{CO}_{2}$ emissions (Von Lützow and Kögelknabner 2009). Thus, our long-term incubation experiment can better reflect the potential respiration for the fast, intermediate, and passive pools during the 182 days.

In recent years, newly emerging evidence has indicated that molecular structure and/or chemical composition do not solely predetermine the persistence of SOC and that instead environmental factors can exert an additional influence upon SOC mineralization (Han et al. 2016). In both eroding and depositional landscapes, the $\mathrm{C}$ in soil can be stabilized against decomposition by two major mechanisms: (a) chemical association of the SOC with mineral surfaces and (b) physical protection of the SOC, either by spatial separation from decomposers or by inaccessibility due to the encapsulation of SOC within soil aggregates (Doetterl et al. 2016).

This study also focuses on the analysis of inner physical protection mechanisms. Soil erosion slackens and breaks down water stable aggregates, thus leading to encapsulated $\mathrm{C}$ being prone to mineralization (Lal 2003). According to the method in this study, the intermediate pool can mainly reflect the contribution of the microaggregate $\mathrm{C}$. Our result showed that the fractions of the intermediate $C$ and the microaggregate $C$ were lowest at the eroding position and highest at the depositional position (Table 1, Fig. 6), providing a reasonable explanation for the observed highest potential soil respiration at the eroding position. In the uppermost topsoil $(0-10 \mathrm{~cm})$, the SOC mineralization rates were higher at the depositional position than at the non-eroding position, reflecting the input of the labile organic matter fractions. Conversely, in the subsoil, the mineralization rates were lowest at the depositional site (Fig. 4), because of 
effective stabilization by physical protection within soil microaggregates. These findings indicate that physical protection mechanisms play a dominant role in the subsoil (i.e., below $10 \mathrm{~cm}$ ) in stabilizing SOC against decomposition. In the depositional topsoil, the input of labile materials plays a major role in soil respiration.

\section{Controls on soil surface respiration fluxes}

Soil surface respiration fluxes can be used as an indicator of the persistence of SOC (Wiaux et al. 2014b). The temporal variability in Rs at a single point can be reasonably described by changes in soil temperature and moisture, while the spatial variability is much more difficult to determine. Relatively inconsistent views about the effect of soil redistribution on the spatial variability of $\mathrm{CO}_{2}$ effluxes exist. Some studies reported higher respiration rates at footslope positions relative to summit and shoulder positions (Reicosky et al. 2005; Webster et al. 2008; Wiaux et al. 2015), but opposite trends were also observed in some regions (Epron et al. 2006; Wei et al. 2014; Zhang et al. 2016).

In our study, the respiration rates were highest at the depositional position, while the Rs/SOC was lowest at that position (Fig. 3). These results support that the SOC at such a footslope is stored along the soil profile and involved in a long-term stabilization process and simultaneously support that the depositional profile emits more $\mathrm{CO}_{2}$ than the summit due to its high amount and quality of SOC. Wiaux et al. (2015) reported that in crop soils, approximately 90 to $95 \%$ of the fluxes originated from the first $10 \mathrm{~cm}$ of the soil profile at the footslope, while at the summit, the first $30 \mathrm{~cm}$ of the soil profile significantly contributed to surface fluxes. These results suggest that the depositional topsoil SOC is prone to be mineralized, and the SOC in this depositional context is stabilized at subsoil depth.

The analysis of the results of the field experiments are in agreement with those of the incubation experiments preliminarily, suggesting that physical protection mechanisms are vital in the processes of SOC decomposition. In addition, a previous study showed that $\mathrm{CO}_{2}$ efflux was also regulated by a complex interplay of different environmental factors, such as soil moisture, soil temperature, and soil porosity (Van Hemelryck et al. 2011). In our study, the protective effects of soil deposition on soil respiration per unit SOC were more remarkable in field conditions than in indoor ones (Fig. 3b and Fig. 4b), most likely due to the impacts of the varied soil water conditions.

Soil moisture is identified as a major environmental driver regulating the spatial variability of soil respiration in many studies (Wei et al. 2014; Wiaux et al. 2014b; Zhang et al. 2016). In general, soil water contents are higher at lower altitudes because of gravity. Previous studies have suggested that excessive soil water can limit SOC decomposition by altering the aeration status and stressing soil microbial activity (Zhang et al. 2016). We observed high water contents at the depositional position, which can obstruct $\mathrm{CO}_{2}$ fluxes, and anaerobic conditions prevail, depressing the activity of aerobes, thus stabilizing SOC as a result.

\section{Conclusion}

This study investigated the impacts of soil erosion on the soil organic carbon and soil respiration in black-soil sloping farmland in Northeast China. The results show that the depositional profiles store 5.9 times more SOC than the eroding profiles and 3.3 times more SOC than the non-eroding profiles. The soils of the depositional profiles were enriched in SOC at subsoil depth, and the SOC contents at the footslope position first increased and then decreased with the soil depth. A linear correlation between the SOC and ${ }^{137} \mathrm{Cs}$ was observed in our study, suggesting that the SOC decreased with increased soil erosion. In the depositional topsoil, the input of labile materials plays a promoting role in soil respiration. By contrast, in the subsoil (i.e., below $10 \mathrm{~cm}$ ), the potential mineralization rates (per unit SOC) were lowest at the depositional position because of effective stabilization by physical protection within soil microaggregates. The field results of the soil surface respiration per unit SOC also suggest that the depositional topsoil SOC is prone to be mineralized and the SOC in this depositional context is stabilized at subsoil depth. These findings support that the $\mathrm{SOC}$ at such a footslope is primarily stored along most of the soil profile (i.e., below $10 \mathrm{~cm}$ ) and is involved in longterm stabilization and meanwhile support that the depositional profile emits more $\mathrm{CO}_{2}$ than the summit due to its high amount and quality of SOC. Furthermore, the high water contents at the depositional position limit decomposition rates and stabilize SOC at the same time.

\section{Abbreviations \\ ${ }^{137}$ Cs: Caesium-137; C: Carbon; $\mathrm{CO}_{2}$ : Carbon dioxide; Rs: Soil respiration; SOC: Soil organic carbon}

\section{Acknowledgments}

This study was supported by the National Key Research and Development Program (2016YFA0602701), National Natural Science Foundation of China (31570468), Changjiang Young Scholars Programme of China (Q2016161), National Youth Top-Notch Talent Support Program, and Fok Ying Tung Education Foundation (151015). The experiments were supported by the Beijing Normal University Jiusan Soil and Water Conservation Station.

\section{Funding}

This study was supported by the National Key Research and Development Program (2016YFA0602701), National Natural Science Foundation of China (31570468), Changjiang Young Scholars Programme of China (Q2016161), National Youth Top-Notch Talent Support Program, and Fok Ying Tung Education Foundation (151015). 


\section{Availability of data and materials}

Data for this manuscript was collected through field sampling and observation in the field/laboratory.

\section{Authors' contributions}

Performed the experiments: TL HZ XW. Conceived and designed the experiments: WY. Analyzed the data: TL HZ WY. Contributed reagents/ materials/analysis tools: SC HF GL. Wrote the paper: TL WY. All authors read and approved the final manuscript.

\section{Ethics approval and consent to participate}

Not applicable.

\section{Consent for publication}

Not applicable.

\section{Competing interests}

The authors declare that they have no competing interests.

\section{Author details}

'State Key Laboratory of Earth Surface Processes and Resource Ecology, Beijing Normal University, Beijing 100875, China. ${ }^{2}$ Le Laboratoire des Sciences du Climat et de I'Environnement, IPSL-LSCECEA/CNRS/UVSQ Saclay, Gif-sur-Yvette, France. ${ }^{3}$ College of Resources and Environment, University of Chinese Academy of Sciences, Beijing 100049, China. ${ }^{4}$ Key Laboratory of Ecosystem Network Observation and Modeling, Institute of Geographic Sciences and Natural Resources Research, Chinese Academy of Sciences, Beijing 100101, China. ${ }^{5}$ Guangdong Province Key Laboratory for Climate Change and Natural disaster Studies, School of Atmospheric Sciences, Sun Yat-sen University, Zhuhai 519082, China. ${ }^{6}$ Southern Marine Science and Engineering Guangdong Laboratory, Zhuhai 519082, China.

\section{Received: 15 February 2019 Accepted: 25 June 2019}

\section{Published online: 02 August 2019}

\section{References}

Berhe AA, Harden JW, Torn MS, John H (2008) Linking soil organic matter dynamics and erosion-induced terrestrial carbon sequestration at different landform positions. J Geophys Res Biogeosci 113:G04039

Berhe AA, Harden JW, Torn MS, Kleber M, Burton SD, Harte J (2012) Persistence of soil organic matter in eroding versus depositional landform positions. J Geophys Res Biogeosci 117:G02019

Dlugoß V, Fiener P, Van Oost K, Schneider K (2012) Model based analysis of lateral and vertical soil carbon fluxes induced by soil redistribution processes in a small agricultural catchment. Earth Surf Process Landf 37:193-208

Doetterl S, Berhe AA, Nadeu E, Wang Z, Sommer M, Fiener P (2016) Erosion, deposition and soil carbon: a review of process-level controls, experimental tools and models to address C cycling in dynamic landscapes. Earth Sci Rev 154:102-122

Doetterl S, Six J, Wesemael BV, Oost KV (2012) Carbon cycling in eroding landscapes: geomorphic controls on soil organic C pool composition and $C$ stabilization. Glob Chang Biol 18:2218-2232

Epron D, Bosc A, Bonal D, Freycon V (2006) Spatial variation of soil respiration across a topographic gradient in a tropical rain forest in French Guiana. J Trop Ecol 22:565-574

Fang H, Sun L, Qi D, Cai Q (2012) Using 137 Cs technique to quantify soil erosion and deposition rates in an agricultural catchment in the black soil region, Northeast China. Geomorphology 169-170:142-150

Fang HJ, Yang XM, Zhang XP, Liang AZ (2006) Using 137 Cs tracer technique to evaluate erosion and deposition of black soil in Northeast China. Pedosphere 16:201-209

Han L, Sun K, Jin J, Xing B (2016) Some concepts of soil organic carbon characteristics and mineral interaction from a review of literature. Soil Biol Biochem 94:107-121

Harden JW, Sharpe JM, Parton WJ, Ojima DS, Fries TL, Huntington TG et al (1999) Dynamic replacement and loss of soil carbon on eroding cropland. Glob Biogeochem Cycles 13:885-901

Jacinthe P-A, Lal R, Kimble J (2002) Carbon dioxide evolution in runoff from simulated rainfall on long-term no-till and plowed soils in southwestern Ohio. Soil Tillage Res 66:23-33
Kuhn NJ, Oost KV, Cammeraat E (2012) Soil erosion, sedimentation and the carbon cycle. Catena 94:1-2

Lal R (2003) Soil erosion and the global carbon budget. Environ Int 29:437-450

Lal R (2004a) Soil carbon sequestration impacts on global climate change and food security. Science 304:1623-1627

Lal R (2004b) Soil carbon sequestration to mitigate climate change. Geoderma 123:1-22

Lal R, Pimentel D (2008) Soil erosion: a carbon sink or source? Science 319:1040-1042

Li T, Wang S, Liu Y, Fu B, Zhao W (2018) Driving forces and their contribution to the recent decrease in sediment flux to ocean of major rivers in China. Sci Total Environ 634:534-541

Liu H, Zhang T, Liu B, Liu G, Wilson GV (2013) Effects of gully erosion and gully filling on soil depth and crop production in the black soil region, Northeast China. Environ Earth Sci 68:1723-1732

Liu L, Zhang K, Zhang Z, Qiu Q (2015) Identifying soil redistribution patterns by magnetic susceptibility on the black soil farmland in Northeast China. Catena 129:103-111

Liu S, Bliss N, Sundquist E, Huntington TG (2003) Modeling carbon dynamics in vegetation and soil under the impact of soil erosion and deposition. Glob Biogeochem Cycles 17:187-194

Lowrance R, McIntyre S, Lance C (1988) Erosion and deposition in a field/forest system estimated using cesium-137 activity. J Soil Water Conserv 43:195-199

Ludwig W, Probst JL, Kempe S (1996) Predicting the oceanic input of organic carbon by continental erosion. Glob Biogeochem Cycles 10:23-41

Nadeu E, Berhe A, Vente Jd, Boix-Fayos C (2012) Erosion, deposition and replacement of soil organic carbon in Mediterranean catchments: a geomorphological, isotopic and land use change approach. Biogeosciences 9:1099-1111

Reicosky DC, Lindstrom MJ, Schumacher TE, Lobb DE, Malo DD (2005) Tillageinduced $\mathrm{CO}_{2}$ loss across an eroded landscape. Soil Tillage Res 81:183-194

Rosenbloom NA, Harden JW, Neff JC, Schimel DS (2006) Geomorphic control of landscape carbon accumulation. J Geophys Res Biogeosci 111:G01004

Schädel C, Luo Y, Evans RD, Fei S, Schaeffer SM (2013) Separating soil $\mathrm{CO}_{2}$ efflux into C-pool-specific decay rates via inverse analysis of soil incubation data. Oecologia 171:721-732

Six J, Elliott ET, Paustian K, Doran JW (1998) Aggregation and soil organic matter accumulation in cultivated and native grassland soils. Soil Sci Soc Am J 62:1367-1377

Smith SV, Buddemeier RW (2005) Fates of eroded soil organic carbon: Mississippi Basin case study. Ecol Appl 15:1929-1940

Stallard RF (1998) Terrestrial sedimentation and the carbon cycle: coupling weathering and erosion to carbon burial. Glob Biogeochem Cycles 12:231-257

Van Hemelryck H, Govers G, Van Oost K, Merckx R (2011) Evaluating the impact of soil redistribution on the in situ mineralization of soil organic carbon. Earth Surf Process Landf 36:427-438

Van Oost K, Govers G, Quine TA, Heckrath G, Olesen JE, Gryze SD et al (2005) Landscape-scale modeling of carbon cycling under the impact of soil redistribution: the role of tillage erosion. Glob Biogeochem Cycles 19:1-13

Van Oost K, Quine T, Govers G, De Gryze S, Six J, Harden J et al (2007) The impact of agricultural soil erosion on the global carbon cycle. Science 318:626-629

Von Lützow M, Kögelknabner I (2009) Temperature sensitivity of soil organic matter decomposition — what do we know? Biol Fertil Soils 46:1-15

Wairiu M, Lal R (2003) Soil organic carbon in relation to cultivation and topsoil removal on sloping lands of Kolombangara, Solomon Islands. Soil Tillage Res 70:19-27

Wang X, Cammeraat LH, Wang Z, Zhou J, Govers G, Kalbitz K (2013) Stability of organic matter in soils of the Belgian Loess Belt upon erosion and deposition. Geophys Res Abstr 64:219-228

Webster KL, Creed IF, Bourbonnière RA, Beall FD (2008) Controls on the heterogeneity of soil respiration in a tolerant hardwood forest. J Geophys Res Biogeosci 113:G03018

Wei S, Zhang X, McLaughlin NB, Liang A, Jia S, Chen X et al (2014) Effect of soil temperature and soil moisture on $\mathrm{CO}_{2}$ flux from eroded landscape positions on black soil in Northeast China. Soil Tillage Res 144:119-125

Wiaux F, Cornelis JT, Cao W, Vanclooster M, Van Oost K (2014a) Combined effect of geomorphic and pedogenic processes on the distribution of soil organic carbon quality along an eroding hillslope on loess soil. Geoderma 216:36-47

Wiaux F, Vanclooster M, Cornelis JT, Van Oost K (2014b) Factors controlling soil organic carbon persistence along an eroding hillslope on the loess belt. Soil Biol Biochem 77:187-196 
Wiaux F, Vanclooster M, Van Oost K (2015) Vertical partitioning and controlling factors of gradient-based soil carbon dioxide fluxes in two contrasted soil profiles along a loamy hillslope. Biogeosciences 12:4637-4649

Wu Y, Zheng Q, Zhang Y, Liu B, Cheng H, Wang Y (2008) Development of gullies and sediment production in the black soil region of northeastern China. Geomorphology 101:683-691

Yoo K, Amundson R, Heimsath AM, Dietrich WE (2005) Erosion of upland hillslope soil organic carbon: coupling field measurements with a sediment transport model. Glob Biogeochem Cycles 19:1721-1730

Yu S, Chen Y, Zhao J, Fu S, Li Z, Xia H et al (2017) Temperature sensitivity of total soil respiration and its heterotrophic and autotrophic components in six vegetation types of subtropical China. Sci Total Environ 607:160-167

Zhang H, Liu S, Yuan W, Dong W, Xia J, Cao Y et al (2016) Loess Plateau check dams can potentially sequester eroded soil organic carbon. J Geophys Res Biogeosci 121:1449-1455

Zhang X, Higgitt D, Walling D (1990) A preliminary assessment of the potential for using caesium-137 to estimate rates of soil erosion in the Loess Plateau of China. Hydrol Sci J 35:243-252

Zhang Y, Wu Y, Liu B, Zheng Q, Yin J (2007) Characteristics and factors controlling the development of ephemeral gullies in cultivated catchments of black soil region, Northeast China. Soil Tillage Res 96:28-41

Wang X, Quine TA, Zhang H, Tian G, Yuan W (2019) Redistribution of soil organic carbon induced by soil erosion in the nine river basins of China. J Geophys Res Biogeosci 124:1018-1031

\section{Publisher's Note}

Springer Nature remains neutral with regard to jurisdictional claims in published maps and institutional affiliations.

\section{Submit your manuscript to a SpringerOpen ${ }^{\circ}$ journal and benefit from:}

- Convenient online submission

- Rigorous peer review

- Open access: articles freely available online

- High visibility within the field

- Retaining the copyright to your article

Submit your next manuscript at $\boldsymbol{\nabla}$ springeropen.com 